\title{
Morphological Characterization by Powder X-Ray Diffraction for the Proposed System xAgI-(1-x)NH $\mathrm{NH}_{4}$
}

\author{
E.J. Cañate-Gonzalez ${ }^{1 \#,}$ W. Fong-Silva ${ }^{2 \#}$, C.A. Severiche-Sierra ${ }^{3 \&}$, Y.A. Marrugo-Ligardo ${ }^{4 \&}$, J. \\ Jaimes-Morales $^{5 \&}$ \\ \#Universidad de Cartagena, GIMIFEC Research Group. Cartagena de indias, Bolívar, Colombia. \\ 1canate2008@hotmail.com \\ 2wfongs@unicartagena.edu.co \\ \&Universidad de Cartagena, MAAS Research Group on Environment, \\ Food and Health. Cartagena de indias, Bolívar, Colombia. \\ ${ }^{3}$ cseveriches@gmail.com \\ 4ymarrugol@unicartagena.edu.co \\ 5jjaimesm@unicartagena.edu.co
}

\begin{abstract}
Conductivity was characterized for the family MI - AgI (where M = $\mathrm{NH}_{4}$ ), which results

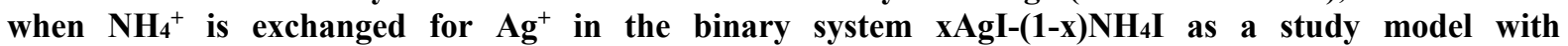
concentrations of $x=0.4,0.5,0.6,0.7,0.8$ and 0.9 . The study samples were cultured using the slow evaporation method, a morphological characterization by powder $\mathrm{X}$-ray diffraction was carried out for the proposed system. The technique allows to observe how the intensities of the peaks corresponding to the crystallographic planes vary and the AgI is used as a reference to perform correlations. The system has a significant variation in molar fractions or low concentrations of $\mathrm{NH}_{4} \mathrm{I}$ presenting high intensity peaks.
\end{abstract}

Keywords- Binary system, X-ray, Ionic conductivity, Ionic crystals.

\section{INTRODUCTION}

The need to produce and store energy for use in modern industry and society, has driven the development of new solid state ionic conductors, which are used as electrolytes in power sources (batteries, fuel cells), biomedical devices, Electrochemical gas sensors and spatial development devices, etc. [1,2] Because many ion systems known today present microstructural variations, it is necessary to investigate not only the properties of the superionic materials, but also those of their precursors, from which, by doping with other elements of ionic radii different from the original ones the population of cargo carriers and their mobility in the resulting systems is increased $[3,4]$.

It has been observed that the replacement of host atoms with other ions produces an increase in conductivity, one of the purposes of this work is to explore further in this direction using the binary system xAgI-(1-x) $\mathrm{NH}_{4} \mathrm{I}$ with concentrations of $\mathrm{x}=0.4,0.5,0.6,0.7,0.8$ and $\mathrm{x}=0.9$ [5]. Expecting that the $\mathrm{NH}_{4}{ }^{+}$ions due to their smaller size with respect to those of $\mathrm{Ag}^{+}$have greater mobility in the crystalline network, increasing the conductivity and reducing the temperature of the conductive phase.

$\mathrm{X}$-ray diffraction is a rapid analytical technique used for phase identification of a crystalline material, measurement of sample purity and it can provide information of unit cell dimensions. X-ray diffraction is based on constructive inference of monochromatic X-rays and a crystalline sample. These X-rays are generated by a cathode ray tube, filtered to produce monochromatic radiation, collimated to concentrate, and directed towards the sample [6].

The ionic conduction process has not been fully understood, and in the last few years a large number of studies have been carried out in this regard, many questions remain to be answered [7]. The objective of this work was to a morphological characterization by powder X-ray diffraction was carried out for the proposed system.

\section{Materials ANd Methods}

\section{Composition Preparation of the samples}

Molar concentrations of 0.4, 0.5, 0.6, 0.7, 0.8 and 0.9 were used, as proposed by Trujillo et al. (2017) [8], silver reagent salts $(\mathrm{AgI})$, ammonium iodide $\left(\mathrm{NH}_{4} \mathrm{I}\right)$ and potassium iodide $(\mathrm{KI})$ were used as reagents in the synthesis, stoichiometrically combined, Table 1 details the preparation where $\mathrm{x}$ is the mole fraction of the reactants. 
Table I. Calculation of system concentrations

\begin{tabular}{|c|c|c|c|c|c|}
\hline \multirow{2}{*}{$\begin{array}{c}\text { No } \\
\text { Combination }\end{array}$} & \multirow{2}{*}{ System } & \multirow{2}{*}{$\begin{array}{c}\text { Atomic } \\
\text { Weight } \mathrm{Pa}\end{array}$} & \multirow{2}{*}{ Concentration } & \multicolumn{2}{|c|}{ Products } \\
\hline & & & & $\mathrm{N} 1=\mathrm{Pa} * \mathrm{C}$ & $\begin{array}{l}\mathrm{N} 2=\mathrm{N} 1 * \text { fact } \\
\operatorname{conv}(1 / 140)\end{array}$ \\
\hline \multirow{2}{*}{1} & AgI & 234.77 & 0.9 & 211.293 & 1.509 \\
\hline & $\mathrm{NH}_{4} \mathrm{I}$ & 144.94 & 0.1 & 14.494 & 0.103 \\
\hline \multirow{2}{*}{2} & AgI & 234.77 & 0.8 & 187.816 & 1.341 \\
\hline & $\mathrm{NH}_{4} \mathrm{I}$ & 144.94 & 0.2 & 28.988 & 0.207 \\
\hline \multirow{2}{*}{3} & AgI & 234.77 & 0.7 & 164.339 & 1.173 \\
\hline & $\mathrm{NH}_{4} \mathrm{I}$ & 144.94 & 0.3 & 43.482 & 0.310 \\
\hline \multirow{2}{*}{4} & AgI & 234.77 & 0.6 & 140.862 & 1.006 \\
\hline & $\mathrm{NH}_{4} \mathrm{I}$ & 144.94 & 0.4 & 57.976 & 0.414 \\
\hline \multirow{2}{*}{5} & AgI & 234.77 & 0.5 & 117.385 & 0.838 \\
\hline & $\mathrm{NH}_{4} \mathrm{I}$ & 144.94 & 0.5 & 72.471 & 0.517 \\
\hline \multirow{2}{*}{6} & AgI & 234,77 & 0.4 & 93.908 & 0.670 \\
\hline & $\mathrm{NH}_{4} \mathrm{I}$ & 144.94 & 0.6 & 86.965 & 0.621 \\
\hline \multirow{2}{*}{7} & AgI & 234.77 & 0.3 & 70.431 & 0.503 \\
\hline & $\mathrm{NH}_{4} \mathrm{I}$ & 144.94 & 0.7 & 101.459 & 0.724 \\
\hline \multirow{2}{*}{8} & AgI & 234.77 & 0.2 & 46.954 & 0.335 \\
\hline & $\mathrm{NH}_{4} \mathrm{I}$ & 144.94 & 0.8 & 115.953 & 0.828 \\
\hline \multirow{2}{*}{9} & $\mathrm{AgI}$ & 234.77 & 0.1 & 23.477 & 0.167 \\
\hline & $\mathrm{NH}_{4} \mathrm{I}$ & 144.94 & 0.9 & 130.447 & 0.931 \\
\hline
\end{tabular}

To Light Diffraction Technique

$\mathrm{X}$-ray diffraction is based on optical interference that occurs when monochromatic radiation passes through a slit of thickness comparable to the wavelength of radiation [9]. It is a basic characterization technique of all types of material with a crystalline structure (not amorphous); this technique is non-destructive, which allows the recovery of the studied material without any type of deterioration [10]. The x-rays diffract the materials as shown in Figure 1 and produce different scanning patterns that function as a "fingerprint" of a crystalline material to allow the identification and quantification of unknown phases in a sample [11]. This technique is commonly used in engineering, geology, and materials science for applications such as corrosion studies, material fabrication, combustion product analysis, mineral identification and network parameter determination [9]. Rapid identification of unknown samples is made possible using a search / match software and a specialized database available in the unit. The samples may be in powder or solid form [6].

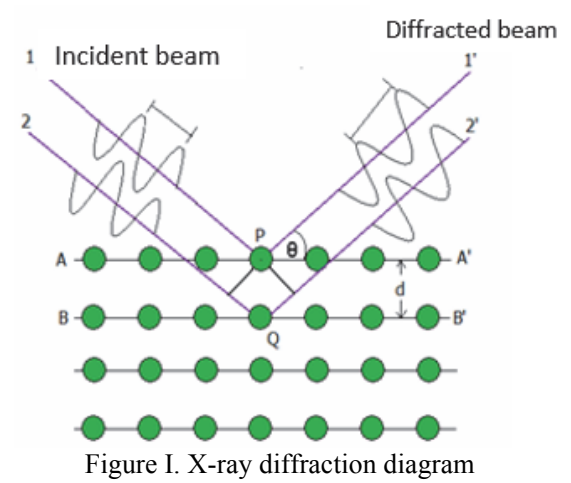


In the case of polymeric solid electrolytes, the technique is widely used to identify and study the degree of crystallinity of the amorphous phase of the substance by scavenging the intensity of the X-rays with the incident angle of the radiation at different temperatures [4].

\section{$X$-ray diffraction analysis}

The X-ray measurements were made in powder on a Panalytical brand diffractometer with an aluminum sample holder coated with a polymer and a $\mathrm{CuK} \alpha$ radiation source. In figures No 2, 3 and 4 correspond to the diffractograms of AgI, $\mathrm{NH}_{4} \mathrm{I},\left(\mathrm{AgI}\right.$ and $\left.\mathrm{NH}_{4} \mathrm{I}\right), \mathrm{xAgI}-(1-\mathrm{x}) \mathrm{NH}_{4} \mathrm{I}, \mathrm{x}=0.4, \mathrm{x}=0.6, \mathrm{x}=0.8$ and the set of all the samples, where the intensities of the peaks corresponding to the crystallographic planes are observed and the $\mathrm{AgI}$ is used as a reference to perform correlations.

\section{RESULTS AND DISCUSSION}

Next we relate the crystallographic planes; (111), (100), (002), (101), (102), (110), (103), (200), (112) and (201). We can observe how there are increases in the relative intensities, but all the peaks are still of a considerable relative intensity so that they could be appreciated in the XRD. Figure 2 shows how the intensities of the peaks corresponding to the planes (100) and (101) vary in the $\mathrm{AgI}$ and $\mathrm{NH}_{4} \mathrm{I}$ samples before replacing $\mathrm{Ag}+$ with $\mathrm{NH}_{4}{ }^{+}$ in the study systems.

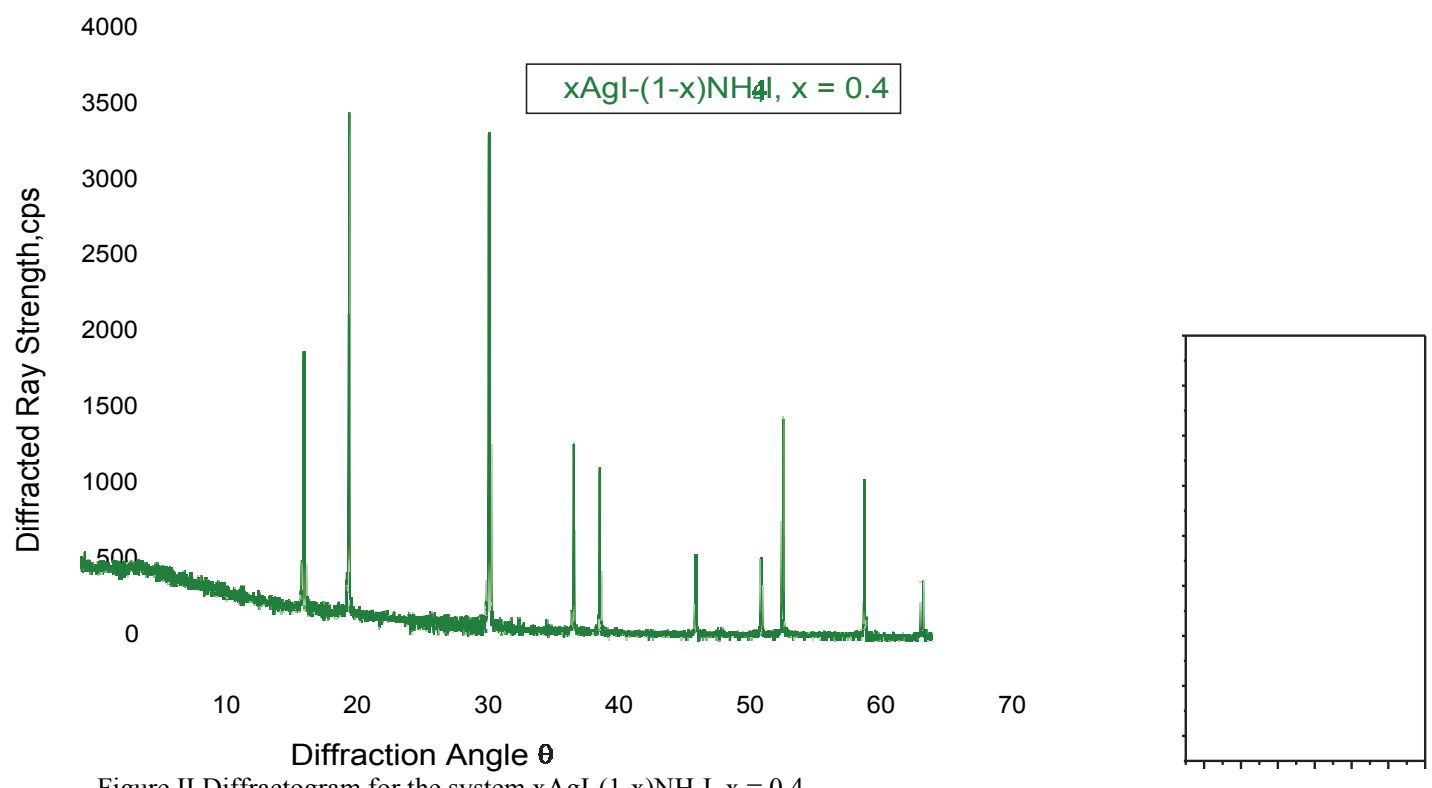

Figure II.Diffractogram for the system xAgI-(1-x) $\mathrm{NH}_{4} \mathrm{I}, \mathrm{x}=0.4$

In particular we can see a considerable change, when $\mathrm{AgI}$ is replaced by $\mathrm{NH}_{4} \mathrm{I}$, as in the case $0.4 \mathrm{AgI}-0.6 \mathrm{NH}_{4} \mathrm{I}$ where the intensity decreased for the plane (100), taking as reference the AgI. For the molar concentration of $\mathrm{x}=$ 0.4 ; its intensity increased approximately 9 times in the plane (101) with respect to the AgI. In the concentration $\mathrm{x}=0.6$ in the plane (101), the intensity has the same value as in the AgI; noting that in planes (101) and (103) of that sample, the intensity increases approximately 9 times and 3 times respectively for each plane; but in the plane (200) it decreased in an intensity of 50 with respect to the AgI. Finally, in the $0.8 \mathrm{AgI}-0.2 \mathrm{NH}_{4} \mathrm{I}$ system, very considerable increases are observed in all the planes that coincide with the AgI, being the case of the peak (100), in which it increases in more than 22 times its intensity. From this we can conclude that the relative intensities of the peaks corresponding to planes (100), (101), (102), (102) and (200) in the system have a significant variation in molar fractions or low concentrations of $\mathrm{NH}_{4} \mathrm{I}$, present high intensity peaks as shown in the values in Table 2, in such a way that they are observed within the XRD. 
Table II. Values of the Diffracted Ray Intensity

\begin{tabular}{|c|c|c|c|c|c|c|c|}
\hline & \multicolumn{7}{|c|}{ Diffraction beam intensities for crystallographic planes } \\
\hline Samples &.$(100)$ &.$(111)$ &.$(101)$ &.$(102)$ &.$(110)$ &.$(103)$ &.$(200)$ \\
\hline $\mathrm{AgI}$ & 2100 & 4800 & 500 & 200 & 4700 & 400 & 250 \\
\hline $\mathrm{NH}_{4} \mathrm{I}$ & 1000 & $\mathrm{x}$ & 4700 & $\mathrm{x}$ & $\mathrm{x}$ & $\mathrm{x}$ & $\mathrm{x}$ \\
\hline $\begin{array}{c}0,4 \mathrm{AgI}- \\
0,6 \mathrm{NH}_{4} \mathrm{I}\end{array}$ & 2000 & $\mathrm{x}$ & 3500 & $\mathrm{x}$ & $\mathrm{x}$ & 1250 & 115 \\
\hline $\begin{array}{c}0,6 \mathrm{AgI}- \\
0,4 \mathrm{NH}_{4} \mathrm{I}\end{array}$ & 2100 & $\mathrm{x}$ & 4600 & $\mathrm{x}$ & $\mathrm{x}$ & 900 & 110 \\
\hline $\begin{array}{c}0,8 \mathrm{AgI}- \\
0,2 \mathrm{NH}\end{array}$ & 2200 & $\mathrm{x}$ & 8600 & 1000 & $\mathrm{x}$ & 1200 & 1000 \\
\hline
\end{tabular}

In general when AgI and NH4I are mixed there are reflections that coincide with the AgI, this fact is observed in Figure 3, according to studies carried out of x-rays there is a slight change in the crystal symmetry from cubic to rhombohedra, in addition there is no appreciable variation in the content and dimension of the unit cell.

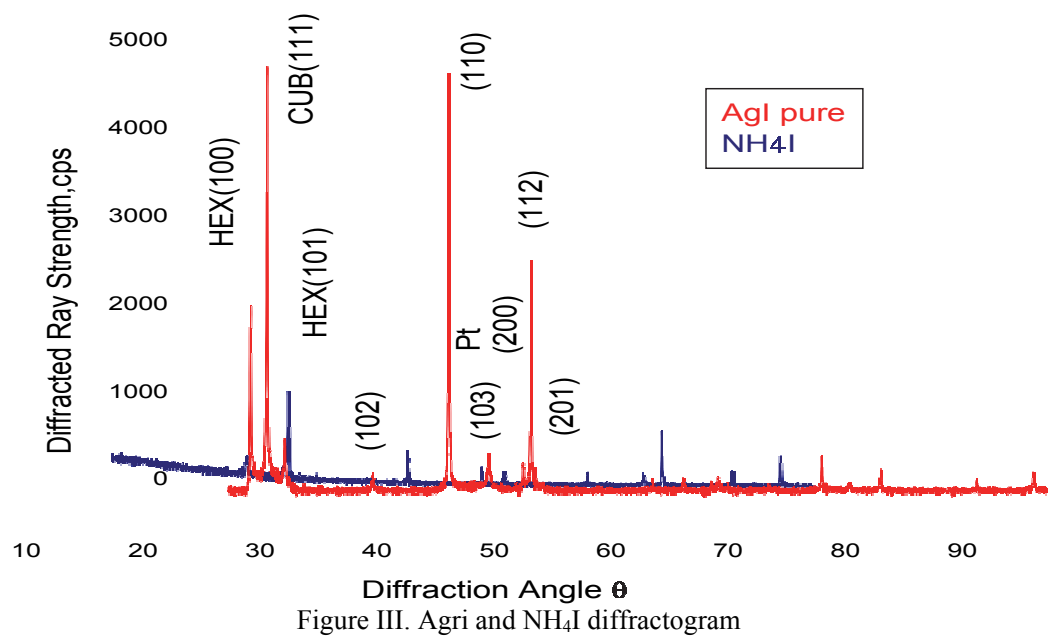

Finally in Figure 4, we see an integration of the diffractograms for all the preparations whose molar concentrations $\mathrm{X}$ were $0.4,0.5,0.6,0.7,0.8$ and 0.9 , in the proposed system $\mathrm{xAgI}-(1-\mathrm{x}) \mathrm{NH}_{4} \mathrm{I}$.

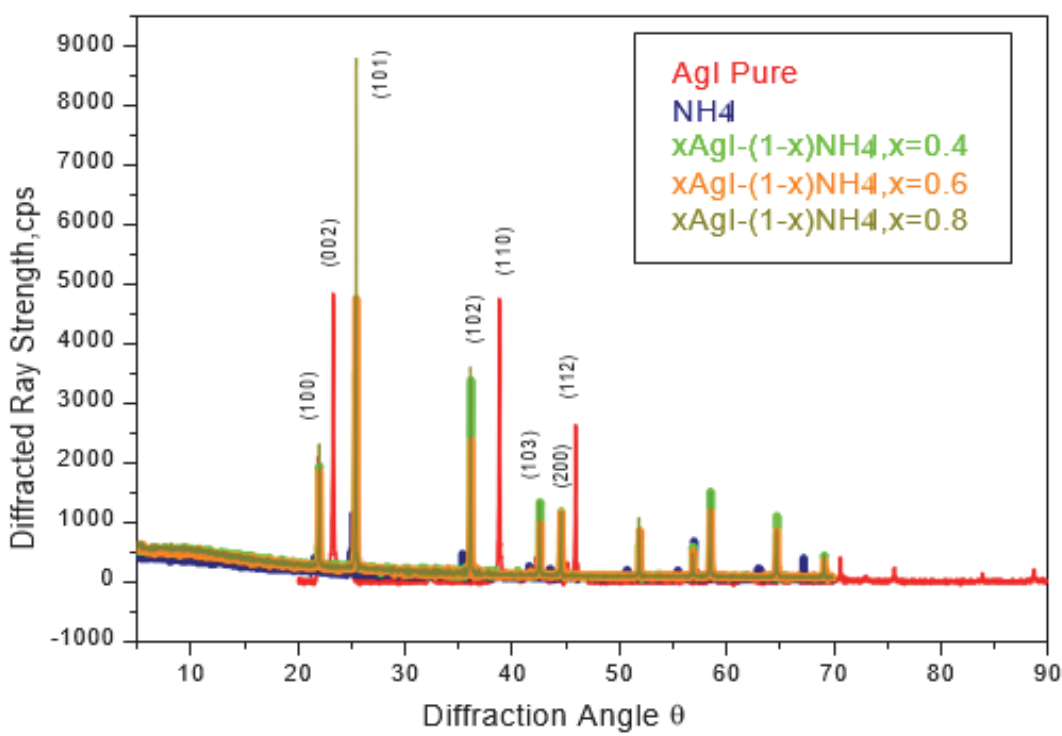

Figure IV. Diffractogram for the $\mathrm{AgI}$ system, $\mathrm{NH}_{4} \mathrm{I}, \mathrm{xAgI}-(1-\mathrm{x}) \mathrm{NH}_{4} \mathrm{I}, \mathrm{x}=0.4,0.6$ and 0.8 


\section{IV.CONCLUSIONS}

According to the X-ray diffraction, we can conclude that the relative intensities of the peaks corresponding to the planes (100), (101), (102), (102) and (200) in the system have an important variation in the fractions molars or low concentrations of $\mathrm{NH}_{4} \mathrm{I}$ in the system, present high intensity peaks; that is, when $\mathrm{AgI}$ and $\mathrm{NH}_{4} \mathrm{I}$ are mixed there are reflections that coincide only with the AgI planes.

\section{References}

[1] E.J. Canate-Gonzalez, W. Fong-Silva, C.A. Severiche-Sierra, Y.A. Marrugo-Ligardo and J. Jaimes-Morales, Determination of thermal properties of the ionic system xAgI-(1-x) $\mathrm{NH}_{4} \mathrm{I}$ by differential scanning calorimetry, Contemporary Engineering Sciences, 11 (2018), 1207-1213

[2] N. Mahato, A. Banerjee, A. Gupta, S. Omar and K. Balani, Progress in material selection for solid oxide fuel cell technology: A review, Progress in Materials Science, 72 (2015), 141-337

[3] E.J. Canate-Gonzalez, W. Fong-Silva, C.A. Severiche-Sierra, Y.A. Marrugo-Ligardo and J. Jaimes-Morales, Complex impedance analysis by Nyquist diagram for the system xAgI-(1-x)NH 4 I, Contemporary Engineering Sciences, 11 (2018), 753-761

[4] C. Lozano, H. Correa, D. Peña and R. Vargas, Modeling the ionic conductivity through the electrolytic phase transition in the NaI-AgI system, Colombian Journal of Physics, 38 (2006), 1535-1538

[5] H. Zea, C.C. Luhrs and J. Phillips, Reductive/expansion synthesis of zero valent submicron and nanometal particles, Journal of Materials Research, 26 (2011), 672-681

[6] G.Velmathi, A Review on Morphological, Structural and Electrical Characterization Techniques of Thin films, International Journal of Engineering and Technology (IJET), 8 (2016), 1925-1935

[7] G. Gregori, R. Merkle and J. Maier, Ion conduction and redistribution at grain boundaries in oxide systems, Progress in Materials Science, 89 (2017), 252-305

[8] J. Trujillo, A. Garcia and R. Ortiz, Measurement of termic and electric properties of the system xAgI-(1-x) NH4I at high temperatures, Journal of Engineering and Applied Sciences, 12 (2017), 3927-3929

[9] M. Pięk, R. Piech and B. Paczosa, All-solid-state nitrate selective electrode with graphene/tetrathiafulvalene nanocomposite as high redox and double layer capacitance solid contact, Electrochimica Acta, 210 (2016), 407-414

[10] Y. Chen, A. Nguyen, M. Orazem, B. Tribollet, N. Pébère, M. Musiani and V. Vivier, Identification of Resistivity Distributions in Dielectric Layers by Measurement Model Analysis of Impedance Spectroscopy, Electrochimica Acta, 219 (2016), 312-320

[11] J. Trujillo, A. Garcia, E. Quiñones and R. Ortiz, Thermal electrical and structural characterizationof MI-AgI (M = Na, Li) systems above room temperatures, Journal of Engineering \& Applied Sciences, 11 (2016), 2709 - 2712 